\title{
B19 シンクロナイズドスイミングのシミュレーション解析 Simulation Analysis of Synchronized Swimming
}

\author{
○畠山剛（東工大院）, 正 中島求（東工大）, 本間三和子（筑波大）, \\ 伊藤浩志（国立スポーツ科学センター）
}

Go HATAKEYAMA, Tokyo Institute of Technology, 2-12-1 Ookayama, Meguro-ku Tokyo Motomu NAKASHIMA, Tokyo Institute of Technology Miwako HOMMA, University of Tsukuba, 1-1-1 Tennodai, Tsukuba Ibaraki Koji ITO, Japan Institute of Sports Science, 3-15-1 Nishigaoka, Kita-ku Tokyo

In synchronized swimming, a swimmer exerts forces on the other swimmers in the water. There have been no methods to analyze such mechanical phenomena to date. Such analytical method is promising to acquire new findings which will be useful for the improvement of performance The objectives of this study were to develop the simulation model for the analysis of synchronized swimming by applying the swimming human simulation model SWUM to it, and to conduct the simulation analysis. In the present study, "lift". (One of the techniques of synchronized swimming) was taken as the target of the simulation. The simulation model for the lift was constructed and a simulation analysis was conducted by inputting the information obtained in the experiment. The simulation result was consistent with the experimental one, indicating the sufficient validity of the simulation.

Key Words: Synchronized Swimming, Sports Engineering, Sports Biomechanics, Simulation

\section{1. 粕言}

シンクロナイズドスイミング（以下，シンクロ）は，複 数の泳者が水中において互いに力を及ぼしあいながら演技 を行う競技である．複数の泳者がいること，水中であるこ と, これらの理由のために，演技中に各泳者にかかる力を 測定することは困難である，そのため，これまでは経験則 によって泳者同士の力の干渉が理解され，指導が行われて きた。これまでにも, シンクロの技術に関する研究は行わ れてきた. Homma and Homma ${ }^{1}$ は, シンク口の基礎的技術で ある巻き足を行う際に，下肢部の各関節がとる軌道を，撮 影実験をもとに明らかにするとともに，巻き足の手法自体 に 2 種類の方法があるとしている. また, 伊藤 ${ }^{2}{ }^{2}$ は, スカー リングを行う際の手のひらの形状について言及し，それら について実験による流体力学的解析を行うことにより，各 形状の特性を明らかにしている。しかし，シンクロのテク ニックに関する研究の多くが，単一の技術に関しての解析 を行ったものである．全ての技術を総合的に評価し，さら に泳者同士の力の相互干渉も含めたシンクロの運動を，シ ミュレーションによって力学的に解析した例は無く, また その方法もこれまで存在しなかった。

水泳に打ける全身のシミュレーション手法として, 中島 $ら^{3)}$ が開発した水泳人体シミュレーションモデルSWUMが 挙げられるが，これまでの SWUM では複数配した人体モデ ルについて, その相互作用を計算し，シンクロの動作を再 現することは不可能であった。そこで本研究では, SWUM を拡張することによりシンクロのシミュレーションモデル を開発し、シミュレーション解析を行うことを目的とする. このようなモデルが開発されれば，従来の経験則に則った 指導方法では得られなかった新たな知見が獲得され，これ によるシンクロのテクニックのパフォーマンス向上が期待 できる.

\section{2. シミュレーションモデルの構築}

まず，複数の人体が複雑に力を及ぼしあう典型的な例と して, 本研究ではシンクロのテクニック「リフト」のシミ ュレーションモデルの構築を行うこととした。 な抗ここで リフトとは, 4 人で行い, 最後に上段の泳者が跳躍するもの を指すこととする．図 1 にシミュレーションモデルの概要 を示す，現在のSWUMには，複数の人体・物体を配し，同 時に解析を行う機能 ${ }^{4)}$ がある. そこで本機能を用いて，4 体

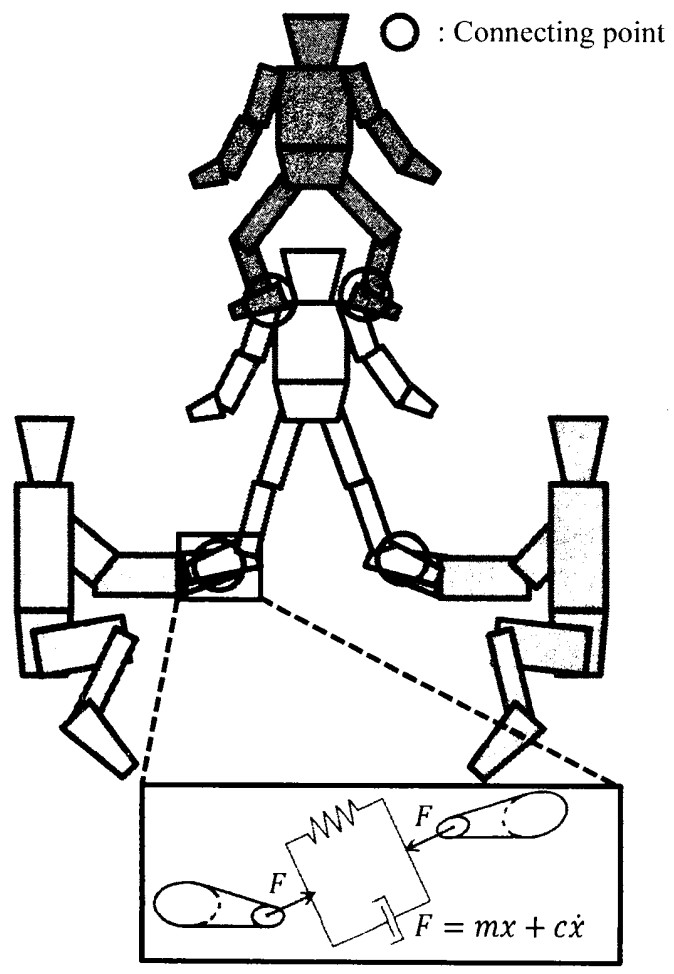

Fig.1 Simulation model for synchronized swimming

日本機械学会〔No.11-17] シンポジウム:スポーツ・アンド・ヒューマン・ダイナミクス 2011 講演論文集 ['11·10.31〜11.2, 京都 $]$ 
の人体を配した後，人体同士の相互作用計算を行うための プログラムを追加で記述し，4人で行うリフトの基本形を構 築した.

人体モデルには簡角運動として各体節の相対運動を与 えた。 また，他の泳者との接触による相互作用については， 接触している体節間を，仮想的なばねとダンパーによって 連結した，具体的に接触定義をしたのは，図１に示すよう に上段の泳者の足部と中段の泳者の肩，そして，下段の泳 者の手部と中段の泳者の足部である.

リフト動作においては，人体を大きく回転させるような 局面がないため, 人体全体の回転運動は強制的に与えるこ ととし，並進のみの運動方程式を解いて人体の並進方向変 位を求めるものとした。

そして，これら 4 つの人体モデルの運動方程式を同時に 同期させて解くことにより, リフトのフォーメーションを 組んだ瞬間から, 最上段の泳者が跳躍するまでの間の, 各 泳者の絶対運動（巻き足による推進など）およびリフトの フォーメーション全体の運動を解析結果として求める.

\section{3. モデルへの入カデータの取得}

シミュレータに入力する泳者の動作データ（関節角）を 取得するため，シンクロ日本代表チームの 4 名の被験者に リフト演技を行わせ, 図 2 に示すように, 3 台の水中カメラ と 2 台の水上カメラによる撮影実験を行った。

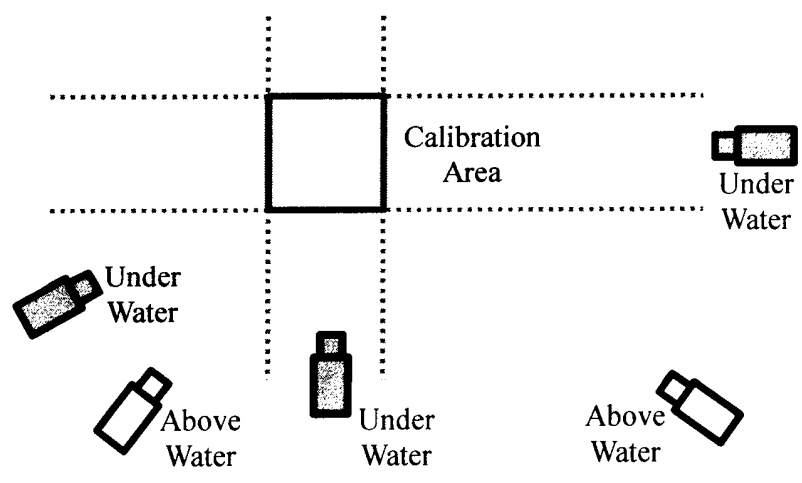

Fig.2 Position of recording devices on filming experiment

キャリブレーションエリアは, 幅 $4.9 \mathrm{~m}$, 奥行 $4.9 \mathrm{~m}$, 樑さ $4.9 \mathrm{~m}$ とした，演技はこの範囲内で行われた，キャリブレー ションツールを図 3 に示す. 映像のサンプリング周波数は $60 \mathrm{~Hz}$ で，この実験映像よりデジタイズを行い，DLT法を用 いて各泳者の身体特徴点の絶対座標情報を取得した。 そし て，その情報をもとに，関節角運動情報を算出した。

また, 被験者全員をデジタルスチルカメラで撮影し, 映 像から身体形状データを取得した。

\section{4. シミュレーション結果}

本シミュレーションでは，モデル同士の接触定義に用い たばねとダンパーを十分に強くし，体節間に生じる相対的 な振動が無視できるほど小さくなるようにした，そして， 実験映像より取得した各泳者の関節角運動情報と, 身体形 状情報を入力した。 そして, リフト中段の泳者の肩の位置 が，実験值の水深と一致する状態を初期位㯰として，解析

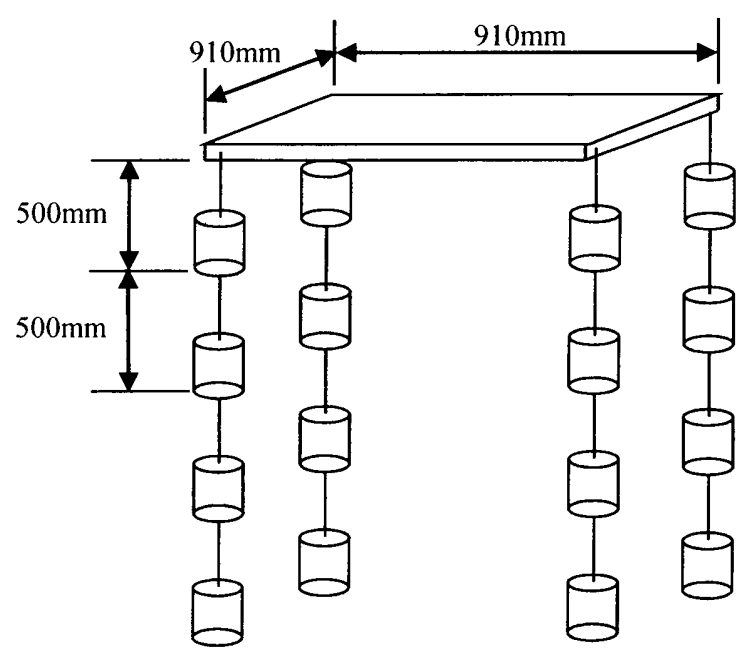

Fig.3 Calibration tool

を行った. 図 4 にリフト中段の泳者の肩の高さの推移につ いてシミュレーション結果と実験值を比較した結果を示す 横軸がリフト動作を始めてからの時間 $[\mathrm{s}]$, 縦軸が中段の泳 者の肩の水深 $[\mathrm{m}] （ 0$ が水面の高さ）を表している。 また， 図 5 にシミュレーション結果のアニメーション映像を示す. 比較のため右側に実験映像を示す。リフト動作を開始して からの時間の流れに沿って上から順に並べた．赤く伸びた 線は，人体の各体節が受けている流体力の大きさと方向を 表している. 入力された関節角運動を行うことにより生じ た推進力によって, リフトのフォーメーションを維持しつ つ 4 人全体が鉛直上方へと移動していく様了が確認できる.

最上段の泳者が跳躍する際，その跳躍の高さは，踏切の 瞬間に踏み台となっている中段の泳者の肩の位嵮と速度に 大きな影響を受ける. 図 4 より動作全体を通して水深, 速 度ともに青線のシミュレーション結果は赤破線の実験結果 とよく一致していることがわかる.

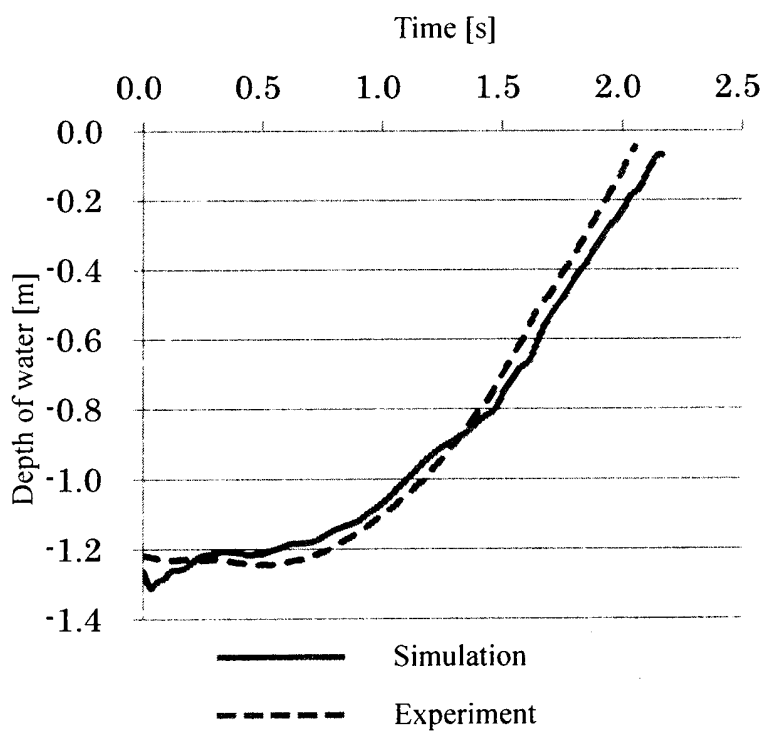

Fig.4 Time history of depth of mid swimmer's shoulder 


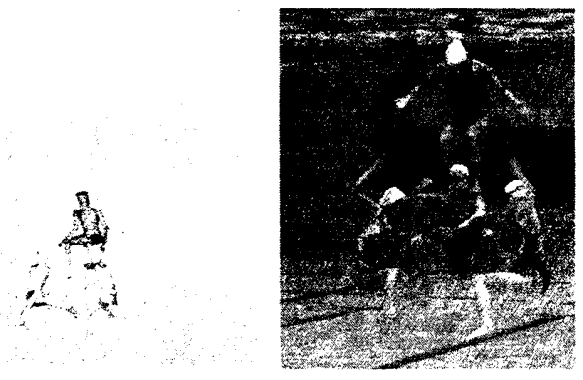

$0.15 \mathrm{~s}$

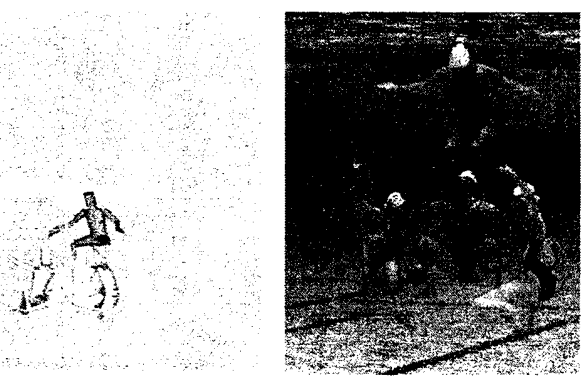

$0.38 \mathrm{~s}$

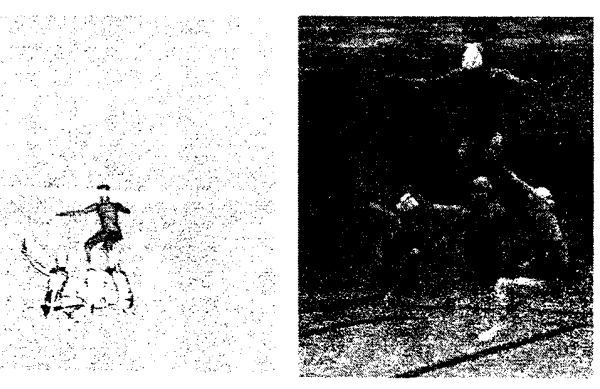

$0.61 \mathrm{~s}$

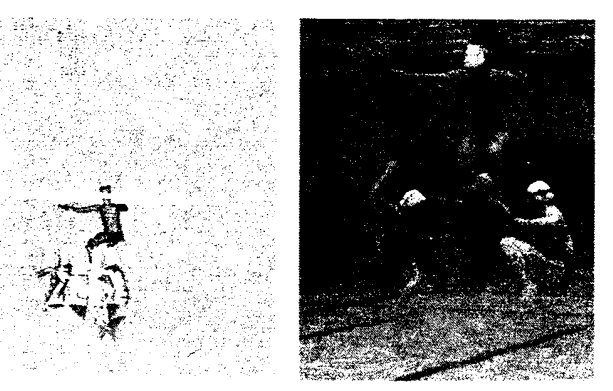

$0.82 \mathrm{~s}$

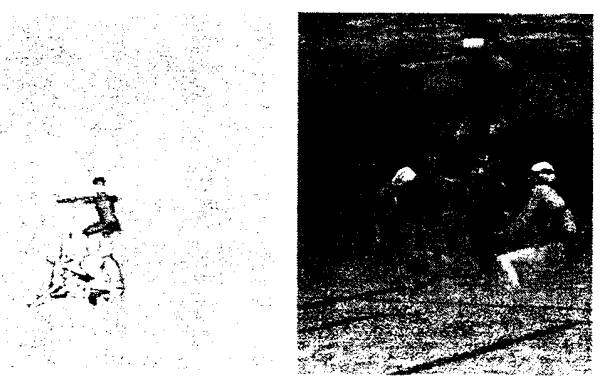

$1.06 \mathrm{~s}$

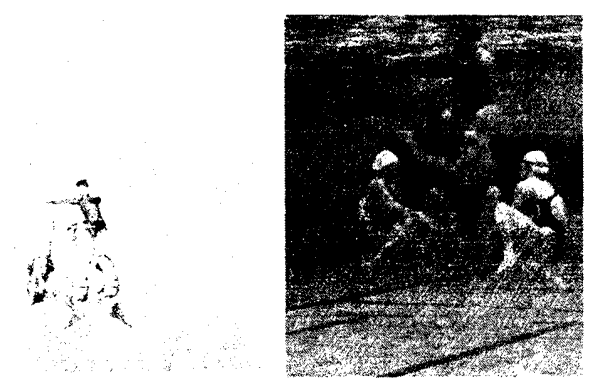

$1.28 \mathrm{~s}$

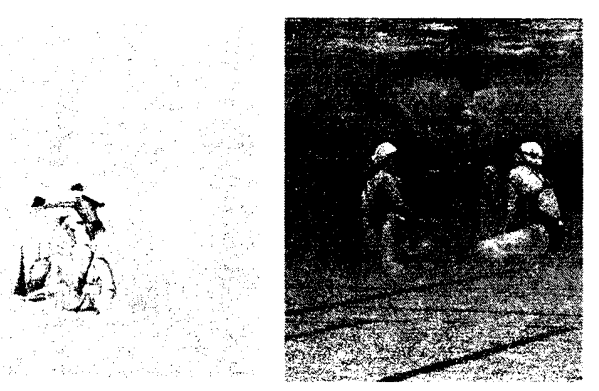

$1.48 \mathrm{~s}$
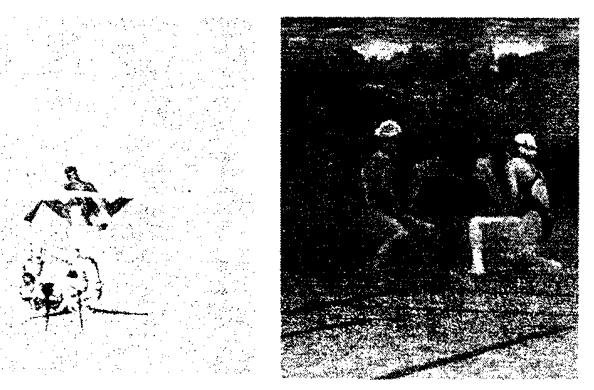

$1.74 \mathrm{~s}$

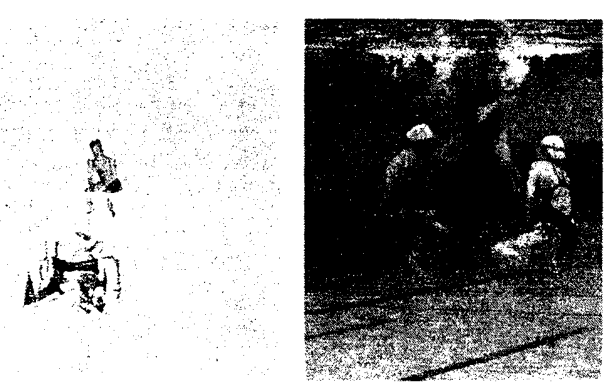

$1.97 \mathrm{~s}$

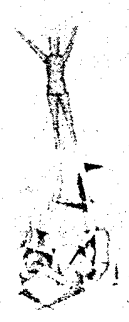

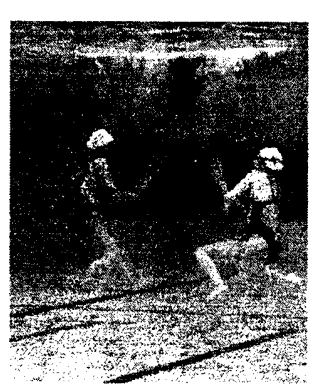

$2.25 \mathrm{~s}$

Fig.5 Animation images of "lift" motion 


\section{5. 結言}

水泳人体シミュレーションモデル SWUM を応用して, 複 数の泳者によるシンクロのリフト動作を表現できるシミュ レーションモデルを構築した。実験より取得した泳者の動 作データおよび身体形状データを入力してシミュレーショ ンを行った. シミュレーション結果は, フォーメーション 全体の水深の変位を高い精度で再現できた。

今後は, 各泳者の運動の変化が最終的な跳躍高さに及ぼ す影響などをシミュレーションにより解明する予定である。

$$
\text { 参考文献 }
$$

(1) Masanobu Homma and Miwako Homma. Three-Dimensional Analysis of the Eggbeater Kick in Synchronized Swimming. Biomechanics and Medicine in Swimming, 40-42. 2005.

(2) 伊藤慎一郎, シンクロナイズドスイミングの手のひら形 状に関する基礎的研究. 日本機械学会論文集 B 編. Vol.73. No.734, 2033-2037, 2007.

(3) 中島求, 佐藤憲, 三浦康郁. 全身の剛体動力学と非定常 流体力を考慮した水泳人体シミュレーションモデルの 開発. 日本機械学会論文集(B 編). 71-705, 1361-1369, 2005.

(4) Motomu Nakashima. Hirokazu Kiuchi and Kenji Nakajima "Multi Agent/Object Simulation in Human Swimming", Journal of Biomechanical Science and Engineering, Vol.5, No.4. 380-387, 2010. 